\title{
Discussion on the Reportage of Left-behind Children from the Perspective of Critical Discourse Analysis: A Case Study of China Daily
}

\author{
Weize Tang ${ }^{1, *}$ Beibei Guan ${ }^{1}$ \\ ${ }^{1}$ Harbin Institute of Technology (Shenzhen), Shenzhen, Guangdong, China \\ "Corresponding author. Email: 377967449@qq.com
}

\begin{abstract}
The acceleration of urbanization has led to the imbalance between urban and rural resource distribution, the continuous flow of rural labor to cities, and the gradual increase of left-behind children. The difficulties in life and education faced by left-behind children have received extensive attention from the government, society, nonprofit organizations, and the media. News reports serve as a key channel for the masses to perceive and understand the status of left-behind children. Based on Fairclough's theory of dialectical relations, this paper builds a corpus to analyze the transitivity, modality of five reports on left behind children in China Daily, and to analyze the discourse strategies at the levels of discourse practice and social cultural practice. This research extends the discourse analysis from the register to the practical field, which expects to arouse widespread public attention to the group of left-behind children, and enhance the reader's critical sensitivity and awareness. From a macroscopic perspective, this research plays a reference role for the media to the construction of the image of left-behind children and the logical construction of news discourses. To a certain extent, this paper can prompt the media to fulfill their obligations of creating an objective, authoritative and authentic information environment for the public. The revelations about the problems pertaining to left-behind children in the media are likely to bring about satisfactory solutions to them.
\end{abstract}

Keywords: Critical discourse analysis, Left-behind children, Dialectical relation theory, Media image.

\section{INTRODUCTION}

The reform and opening-up, the advancement of China's industrialization and the rapid flow of population have encouraged more and more farmers to migrate to the cities to make a living, hence the formation of a large group of "migrant workers". However, due to the unstable work, limited living conditions, and the constraints of relevant national systems, these workers are often unable to take their young children with them and fail to take good care of them. These kids who are forced to stay in their hometowns are christened left-behind children. [1] According to China News Agency, as of the end of August 2018, there were 6.97 million left-behind children in rural areas across the country. [2] Left-behind children are the vulnerable groups in the society. After their situations are disclosed to the public, they are gradually concerned by the party, the state and the broad masses, and become a hot topic of news reports. With the increasing number of left-behind children, the problem is becoming more and more serious, which needs the attention from the whole society for solutions. Therefore, it is necessary to strengthen the research on left-behind children.

As the mainstream media outlet in China, China Daily enjoys high public credibility. It is a platform for China's diplomatic propaganda and a window into the social contexts of the nation. Its reports on left-behind children have a profound impact on the public's cognition and emotional attitudes. Therefore, this paper selects five reports on leftbehind children in China Daily in 2021, takes Fairclough's dialectical relationship theory as the theoretical framework, builds a corpus, and analyzes the tendency and construction path of the news discourses in the construction of left-behind children's media image. The purpose of this paper is 
to examine the value-orientation of left-behind children reported by China Daily, which is conducive to building an objective media image of left-behind children for the public in the future. This paper discusses how China Daily employs certain discursive symbols to represent left-behind children and solidify such images in an impartial way so as to guide the public towards a rational comprehension of this serious social issue. This research expects to arouse the public's attention and strengthen the reader's critical sensitivity and awareness.

\section{THEORETICAL BASIS AND RESEARCH METHODS}

Critical discourse analysis (CDA) is an important method of discourse analysis. It aims to reveal the power and ideology hidden behind the text by analyzing the linguistic features of the text, and to reveal their relationship. [3] Fairclough, a representative figure in critical discourse analysis, proposes the "three-dimensional concept of discourse" model. Within this model, saliency language data is used as an auxiliary tool for the qualitative analysis of language features in the text analysis stage. In the discourse practice stage, this study explains the relationship between text and discourse through intertextuality theory. In the stage of social practice, this research explains the relationship between discourse and social context, and the relationship between the discourse and ideology of the news reports on left-behind children.

\section{RESEARCH IN CHINA AND FOREIGN COUNTRIES}

The emergence of large-scale left-behind children in China is closely related to the dual urban-rural structure which has gradually emerged with the development of industrialization and urbanization. [4] Left-behind children are not unique to China. Large international laborexporting countries such as European nations, Ethiopia, Mexico, Philippines and India also have the situation of population flow and long-term separation between parents and children. Brenda S.A. Yeoh from National University of Singapore (2019) describes how left-behind children in Indonesia and the Philippines cope with the changes in their daily lives brought about by migration and return of their parents, revealing the left-behind children's strategies for managing daily life changes in their parents' long-term absence.
Alina botezat (2020) studies the causal effects of parental migration on the education, physical and mental health of left-behind children aged 11-15 in Romania.

As for the left-behind children in China, most scholars, sensitive to the specific social context of the nation, tend to address the issue by analyzing the related themes, sources and images in selected websites and newspapers. [5] Wu Haiyan (2020) analyzes the construction process of left-behind children's media image, and finds that the image of left-behind children constructed by China News Network is three-dimensional and pluralistic. Guo Congli (2020) conducts a critical discourse analysis of the reports on left-behind children in People's Daily and Guangming Daily, and finds that the media has created a negative image for the leftbehind children, and the reports on the left-behind children are modelled in terms of reporting issues and genres. Sun Huanhuan (2016) adopts van Dyck's news discourse theory and finds that the reports present a dual and narrative characteristic [6], highlighting the differentiated characteristics of left-behind children and the constructed images of left-behind children.

In conclusion, the academic studies of leftbehind children mostly focus on mainstream media or famous metropolis newspapers and overlook those written in English like China Daily. However, in today's globalization, such domestic English portals in China serve as an important window for foreign countries into China's actual social contexts. Against this international backdrop, it is necessary to explore how China Daily reports the heatedly discussed issue of left-behind children through critical discourse analysis.

\section{CASE ANALYSIS AND DISCUSSION}

This paper selects five news reports on leftbehind children in China Daily in 2021, and uses a self-built corpus containing 2,400-word news discourses for inductive analysis.

\subsection{Statistical Analysis of High Frequency Words in News Reports}

This research first uses the uses "Wordart", a word cloud tool, to generate a vocabulary cloud map, as shown in "Figure 1". 


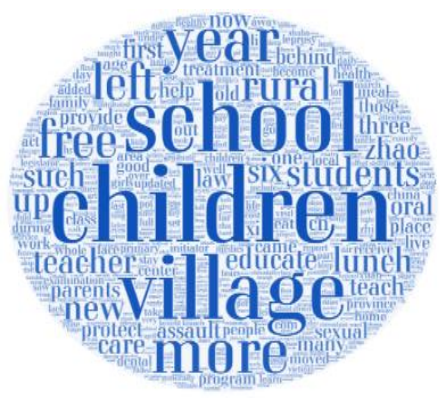

Figure 1 High-frequency words of "left-behind children".

According to the word cloud chart statistics, the author selects the top 10 high-frequency words in the report, which obtain children, school, village, rural, more, year, educate, lunch, free, student, constructing a framework for the status quo of leftbehind children. According to the part of speech, they can be divided into two categories: noun and adjective. Nouns mainly describe the living environment of left-behind children, as well as the material and educational problems closely related to them. The adjectives mainly indicate the betterment of the living conditions of the leftbehind children with the help of the government and society. However, it is worth noting that although "children" is the most frequent word, the subject of the report focus more on the government, rural teachers, and public welfare organizations than the left-behind children themselves. The themes of the reports are more concentrated on the active actions taken by governments or social organizations, but there are fewer reflective reports from the national system.

\subsection{Discourse Analysis}

\subsubsection{Transitivity}

It can be seen from the "Table 1" that among the six types, material process accounts for the largest proportion, with an average of $52.63 \%$. This process usually describes the development of events. Relational process ranked second and verbal process ranked third, in which direct speech dominates. All the three kinds of processes can reflect the authenticity and objectivity of news reports, but most actions or utterances are not made by left-behind children themselves, for example:

- The initiative, regarded as a people's livelihood project, has expanded from Guizhou to 26 other provinces and regions, helping more than 370,000 needy students eat steaming lunches at no cost.

- Fang Kunyou, 51, principal of the school, said through tears of emotion: "Over the years, I've been very pleased to see our children enjoy eating in the canteen and have good health to receive a good education."

Most action senders focus on the social roles such as doctors, officials, volunteers, welfare workers, etc., which makes the texts center around the behavior of these active givers. Left-behind children only appear as passive receivers. The texts show the image of left-behind children accepting the care of the government and society passively and silently. The weak and passive position of leftbehind children in the reports shows that China Daily mainly focuses on what the government and society have done for left-behind children from the official perspective, neglecting the subjective positions and discourses of left-behind children.

Table 1. Transitivity distribution in the report of "left-behind children"

\begin{tabular}{|l|l|l|l|l|l|l|l|l|l|}
\hline & \multicolumn{2}{|c|}{ Material process } & \multicolumn{2}{c|}{ Relational process } & \multicolumn{2}{c|}{ Verbal process } & \multicolumn{2}{l|}{ Mental process } & Total No. \\
& No. & Per. & No. & Per. & No. & Per. & No. & Per. \\
\hline Text1 & 12 & $57.14 \%$ & 5 & $23.81 \%$ & 4 & $19.08 \%$ & 0 & & \\
\hline Text2 & 25 & $53.19 \%$ & 11 & $23.40 \%$ & 8 & $17.02 \%$ & 3 & $6.38 \%$ & 47 \\
\hline Text3 & 9 & $50 \%$ & 6 & $33.33 \%$ & 1 & $5.56 \%$ & 2 & $11.11 \%$ & 18 \\
\hline Text4 & 15 & $45.45 \%$ & 8 & $24.24 \%$ & 9 & $27.28 \%$ & 1 & $3.03 \%$ & 33 \\
\hline Text5 & 9 & $64.29 \%$ & 2 & $14.29 \%$ & 3 & $21.43 \%$ & 0 & 14 \\
\hline Average & & $52.63 \%$ & & $24.06 \%$ & & $18.79 \%$ & & $4.51 \%$ & 133 \\
\hline
\end{tabular}

\subsubsection{Modality}

Modality is of great significance for clarifying the intention of the editor and the relationship between the journalist and the reader of the news.[7] This paper explores the hidden power in the discourses of the government and left-behind children, journalists and readers from two aspects: modality orientation and modality types.("Table 2") 
Table 2. The distribution of modality types

\begin{tabular}{|l|l|l|l|l|}
\hline & \multicolumn{1}{|c|}{ Probability } & \multicolumn{1}{|c|}{ Capability } & \multicolumn{1}{c|}{ Inclination } & Obligation \\
\hline Frequency & 6 & 10 & 0 & 13 \\
\hline Percentage & $20.69 \%$ & $34.48 \%$ & & $44.83 \%$ \\
\hline
\end{tabular}

After the text analysis, the author finds that Capability and Obligation account for the largest proportion. Most modal types tend to be obligation, and the modal value is higher. [8] In order to weaken their subjective views and make news reports more objective, journalists tend to combine their own views and modalities. For example:

- $\quad$ "The very first step is to let children know what sexual assault is and how they should react when facing such incidents," he said.

- The benefit of village teachers and service workers involving left-behind children should be safeguarded to maintain their passion for the work, she said, adding that local governments should work to manage the operations.

Regarding the obvious problems of left-behind children, China daily adopts a clear attitude to convey relevant policies and suggestions, so that it not only promotes the image of China as a big country, but also conveys its own values and worldview to the world. Modal verbs show the responsibilities and measures of various social organizations in dealing with the problems of leftbehind children. On the one hand, such language strategies construct the image of an authoritative government and enhance the discourse power of the government and institutions; on the other hand, it reflects the unequal relationship among journalists, left-behind children and readers, and fails to do justice to the status and role of the general public in such news.

\subsection{Discourse Practice Level Analysis}

In the following corpus analysis, the proportion of indirect speech is larger than that of direct speech. ("Table 3") For example:

- Nong said he was scared by the anxious atmosphere at the health center when he first arrived in the village.

- Xuan said that it's possible the children are generally unaware of oral health

Table 3. Distribution of direct speech and indirect speech knowledge and do not pay attention to oral hygiene.

The use of a large number of indirect quotations in the reports may be due to the fact that "making a better China story and making China voice better heard" is an important task to strengthen the construction of China's international communication capacity. Then China Daily serves as a platform for diplomatic propaganda, and its news reports want to introduce readers into the context in the form of storytelling, so as to arouse readers' resonance and better shape the national image. At the same time, through the analysis of these quotations, the author finds that most of the direct quotations come from teachers, volunteers and relevant officials. For example:

- One of the sponsors of the charitable project, Zhang Yan, said: "After 10 years, we can see the light of wonder in the children's eyes. Their hope is the whole point."

- $\quad$ "When I saw that the children were healthy and lively and their eyes were full of eagerness to learn, I could not run away, no matter how scared I was," Nong recalled.

From the above news discourse, the use of direct speech not only strengthens the authority and persuasiveness of the news [9], but also makes the readers feel that the government organizes forces from all walks of life to help left-behind children and solve their problems through discourse representation. Although some direct words of leftbehind children are used in the report, they are few in number. It can be seen that while such reports focus on showing how to help or support leftbehind children, they weaken the voice of leftbehind children. The reports lack in-depth interviews from the perspective of left-behind children. Through the selective news discourses, China Daily has created a positive image of the government at the cost of a comprehensive image of left-behind children.

\begin{tabular}{|l|l|l|l|l|}
\hline & direct speech & proportion & indirect speech & proportion \\
\hline Text1-5 & 11 & $44 \%$ & 14 & $66 \%$ \\
\hline
\end{tabular}




\subsection{Social and Cultural Practice Level Analysis}

Fairclough points out in his book Discourse and Social Change that discourse analysis is based on the analysis of several processes, namely text production, text distribution and text assessment. However, all these processes are social construction [10]. This paper combines the political and social background of the discourses to analyze the hidden power and ideology.

First, political power has an influence on the contents of the news reports on left-behind children. As a platform for China's foreign publicity that is under the restriction and guidance of political factors, China Daily focuses on the government policies and a certain group of leftbehind children, but generally overlooks the tracking reports of individual left-behind children. At the same time, the discourse describing the status quo of left-behind children rarely adopts the voices of the children, and the reports more regard the left-behind children as a whole, while neglecting to explore the uniqueness of individual left-behind children, resulting in a single, conventional mode of news reports.

Secondly, social attention is the foundation of the news industry. With the explosive growth of mobile phones and individual users, the media of news dissemination has undergone tremendous changes. Therefore, news topics with high social attention are often given priority. For marginalized news topics such as left-behind children, China Daily reports them infrequently and does not fully show the current situation of Chinese left-behind children on the international stage.

Finally, social attention can ensure the authenticity of left-behind children's news reports to a certain extent. China Daily targets both domestic and international readers. The attention of the broad masses can stimulate the news industry to report on left-behind children's news so that the media may diversify the topic selection of left behind children, enrich the theme types of reports, and present the appearance of left behind children more comprehensively.

\section{CONCLUSION}

From the perspective of critical discourse analysis, this paper combs and analyzes China Daily's reports on left-behind children, in order to summarize its discourse construction path and discover the problems that exist in the process of media reportage on left-behind children. Through the sample analysis, this paper finds that China Daily, as a platform for external publicity, mainly focuses on the positive reporting theme of the government and society's care for left-behind children from the official perspective. The descriptions in the news are relatively objective and the corresponding discourse strategies are instrumental in introducing readers into story-like reports and effectively arousing their strong concern for left-behind children. However, in most reports, the left-behind children appear in the role of action recipients, who are passive and disadvantaged groups who do not have a strong right to speak. At the same time, China Daily relies too much on official sources, neglecting the voice of left-behind children and individual differences, resulting in a lack of vivid personal images of leftbehind children. In this light, this paper suggests that China Daily should focus more on the individual left-behind children in the future by encouraging them to express their innermost feelings and recording them in actual journalistic reports. It is incumbent upon China Daily and many news portals alike to assume social responsibilities for reporting on left-behind children in an authentic and comprehensive way. In addition, the news media is supposed to keep alert to the hidden information behind the related incidents so as to better show the status quo of left-behind children to both Chinese and foreign people.

\section{AUTHORS' CONTRIBUTIONS}

This paper is completed by Weize Tang; Beibei Guan contributed to revising and editing.

\section{REFERENCES}

[1] Tanshen., "A review of studies on left behind children in rural China", Social Science in China Press. 2011: (01), 138-150.

[2] Duan Chengrong, "Basic situation of survival and development of rural left behind children in China-Analysis based on the sixth census data", Population Journal. 2013.

[3] Fairclough. N., "Discourse and Power", Longman Publishing. 1992: 160-161. 
[4] Ye Jingzhong, "To solve the problem of leftbehind children, look forward to a coordinated urban-rural development model", China community newspaper. 2016.

[5] Xu Xingxing, "Research on documentary film about left-behind children in rural areas", Xinjiang University. 2016.

[6] Sun Huanhuan, "Research on the Media Image of Left-behind Children", Central China Normal University. 2016.

[7] Zhang Delu, "Exploration of the Comprehensive Theoretical Framework of Multimodal Discourse Analysis", Foreign Languages in China. 2009.

[8] Ding Hegen, "The Theory, Object and Method of Discourse Analysis of Mass Media", Journalism \& Communication. 2004.

[9] Xinbin \&Gao Xiaoli "Critical Discourse Analysis: Goals, Methods and Trends", Foreign Languages and Their Teaching. 2013.

[10] Fairclough. N., "Discourse and Social Change", Cambridge: Polity Press. 1992: 2829. 